\title{
COMMENTARY: \\ The Global Framework for Climate Services
}

\author{
Chris Hewitt, Simon Mason and David Walland
}

\section{There is a growing and urgent need to improve society's resilience to climate-related hazards and better manage the risks and opportunities arising from climate variability and climate change.}

S ociety has always had to deal with climate variability, including extreme weather and climate events, but can no longer assume that past climatic conditions are indicative of current and future conditions. The combined effects of climate change and of increasing vulnerability and exposure to hazards due to migration, infrastructural development and changing land use present unprecedented challenges to society. To serve society's needs better we have to improve our understanding and predictions of climate further and dramatically improve our use of climate information.

Many countries are attempting to address these challenges by developing climate service capabilities. A climate service can be considered as the provision of climate information in such a way as to assist decision-making. The service needs to be based on scientifically credible information and expertise, have appropriate engagement from users and providers, have an effective access mechanism and meet the users' needs. Effective climate services facilitate climatesmart decisions that reduce the impact of climate-related hazards and increase the benefits from benign climate conditions. The status of climate services varies widely across the globe - some countries have well-developed services, whereas others have very few or even none. In some cases information is available but is not accessed. Developing countries particularly suffer from shortcomings in capacity.

The World Climate Conference- 3 in 2009 brought together Heads of States, government ministers, industry representatives, and scientific and technical experts to discuss the needs for enhanced climate services and improved coordination ${ }^{1}$. The Conference called for the implementation of a

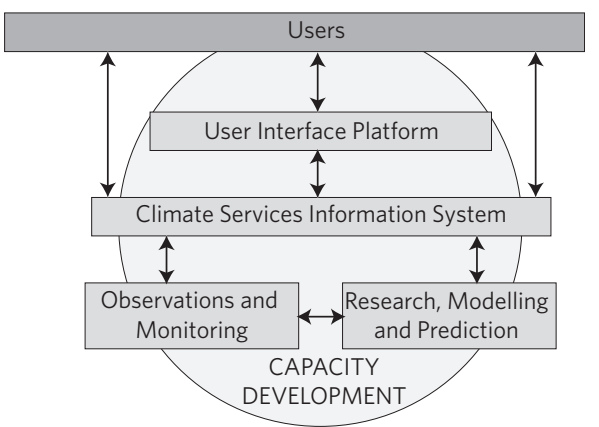

Figure 1 | Schematic showing the components of the Global Framework for Climate Services. Arrows indicate the main flows of information. Figure reproduced with permission from ref. 3, (c) 2011 World Meteorological Organization.

Global Framework for Climate Services (hereafter called the Framework) to strengthen and coordinate existing initiatives and develop new infrastructure where needed to meet society's climate-related challenges. Through subsequent widespread international consultation $^{2,3}$, an implementation plan has been drafted that will be discussed at an Extraordinary Session of the World Meteorological Congress in late October 2012. Approval will be sought from governments for immediate implementation.

\section{Challenges, goals and benefits}

The following are key challenges that implementation of the Framework will address: (1) access to climate services needs to be established and/or improved in all countries; (2) the capacity to deal with climate-related risks is lacking in many countries; (3) the availability and quality of climate data are inadequate in many parts of the globe; (4) users and providers need to interact more effectively; and (5) the quality of climate services needs improvement to match user requirements better.

The vision of the Framework is to enable society to better manage the risks and opportunities arising from climate variability and change, especially for those who are most vulnerable to climate-related hazards. This will be done through developing and incorporating science-based climate information and prediction into planning, policy and practice.

The Framework has five overarching goals: (1) reduce the vulnerability of society to climate-related hazards through better provision of climate information; (2) advance the key global development goals through better provision of climate information; (3) mainstream the use of climate information in decisionmaking; (4) strengthen the engagement of providers and users of climate services; and (5) maximize the utility of existing climate-service infrastructure.

The benefits of implementing the Framework need to be demonstrated at an early stage to sustain the commitment of decision-makers, providers and potential funders. Effective development and use of climate services will be of great value for decision-making in many economic and social sectors. This value has not yet been properly assessed by providers or users, although some attempts at quantification have been made ${ }^{4,5}$.

The following eight principles will be used to guide implementation of the Framework: (1) all countries will benefit, but priority shall go to building the capacity of developing countries vulnerable to the impacts of climate change and variability; (2) greater availability of, access to and use of enhanced climate services for all countries will be ensured; (3) activities will address global, regional and national levels; (4) operational climate services will be the core element; 
(5) climate information is primarily an international public good provided by governments, which will have a central role in the Framework's management;

(6) the free and open exchange of

climate-relevant data (including socioeconomic and environmental data), tools and scientifically based methods will be promoted while respecting national and international policies; (7) the Framework will facilitate and strengthen, not duplicate activities; and (8) the Framework will be built through user-provider partnerships that include all stakeholders.

\section{Roadmap for improvements}

The Framework will be built on four components (a provider-user interface; information systems; observations and monitoring; research, modelling and prediction), and capacity development will encompass all four components (Fig. 1).

The User Interface Platform is a structured means for users, climate researchers and information providers to interact. This interface is the most novel and least developed component. Its purpose is to involve users in identifying needs, developing appropriate products, defining capacity development requirements and influencing the direction of observational investments and research efforts. The Climate Services Information System is the mechanism through which information about climate (past, present and future) is routinely collected, stored and processed to generate products and services that inform decision-making across a wide range of climate-sensitive activities. The Observations and Monitoring component collects, manages and disseminates climate observations and other necessary data, including relevant metadata. The Research, Modelling and Prediction component works to improve the scientific quality of climate information, and to provide an evidence base for the impacts of climate change and variability and the costeffectiveness of using climate information.

The Framework will support and promote effective collaboration with global, regional and national stakeholders and efforts. At the global level the focus will be on defining the large-scale activities required for successfully developing and delivering climate services. At the regional level, the focus will be on cooperation with multilateral efforts to address regional needs, for example through knowledge and data exchange, infrastructure development, research and training and by providing services regionally. At the national level, the Framework will be developed and coordinated by each national government and key national organizations to ensure that all domestic participants can express their requirements for climate services.

\section{Early focus and activities}

In the first few years, the focus will be on developing and delivering services in four priority areas that present the most pressing and immediate opportunities for bringing benefits to human safety and well-being. These priority areas are agriculture and food security, disaster risk reduction, health and water resources. The priority areas are closely aligned to the needs and goals addressed by the Millennium Development Goals, the Hyogo Framework for Action and the United Nations Framework Convention on Climate Change. Key deliverables over the first two years include: implementing the necessary governance, management and reporting frameworks; implementing initial projects; developing regional and national capabilities; and engaging user communities. As the Framework evolves, the needs of users in other areas will be addressed and all climate-sensitive sectors stand to benefit.

\section{The vision ... is to enable society to better manage the risks and opportunities arising from climate variability and change.}

The Framework will be implemented by coordinating and promoting activities and projects that help to achieve its goals. Many of these activities will continue efforts already being made but will be fitted into a coherent framework with common goals. New projects will be devised and selected using criteria aligned with the principles outlined above and will address identified gaps, focusing on the initial priority areas.

Partnerships will be essential, with active engagement from key organizations including United Nations agencies, international organizations, existing climate service-related programmes, users, providers, donors, governments, non-governmental organizations, private sector organizations and national meteorological and hydrological services, many of whom have a strong weather service remit but not a strong climate service remit.
The largest investment will be from continuing current commitments to existing climate services. Additional investment will be required particularly to help developing countries and address funding gaps. Sources of funding outside national budget processes will be required. Such sources may include development banks, climate funds (such as the Adaptation Fund, Climate Investment Funds, Green Climate Fund and the Global Environment Facility), United Nations agencies, overseas development assistance, regional economic groupings, national programmes and the private sector. Obtaining recognition from governments that climate services have considerable value and deserve support will be part of the challenge. In developed countries awareness of the contribution of climate services to economic development will need to be raised to encourage further investment.

The Global Framework for Climate Services represents a major, concerted and coordinated global effort to improve the wellbeing of all parts of society vulnerable to climate variability and climate change. There are already mechanisms and institutions that provide climate services, as well as other activities and development plans that address climate issues, but these are insufficiently linked. The Framework will be aligned with such activities, will benefit from them and vice versa, but will go beyond them by creating the structures needed to deliver needs-driven climate services across the globe.

Chris Hewitt ${ }^{* 1}$, Simon Mason ${ }^{2}$ and David Walland ${ }^{3}$ are at the ${ }^{1}$ Met Office, Hadley Centre, Fitzroy Road, Exeter, Devon EX1 3PB, UK, ${ }^{2}$ International Research Institute for Climate and Society, The Earth Institute at Columbia University, Monell Building, 61 Route 9 W Lamont Campus, Palisades, New York, New York 10964-8000, USA, and ${ }^{3}$ Climate Information Services Program, Bureau of Meteorology, PO Box 1289, Melbourne, VIC 3001, Australia.

*e-mail:chris.hewitt@metoffice.gov.uk

References

1. World Climate Conference-3 Conference Statement (WCC3, 2009); available via http://go.nature.com/bEqMA6

2. World Meteorological Organization Abstracts of the Technical Conference on Changing Climate and Demands for Climate Services for Sustainable Development (WMO, 2010); available via http://go.nature.com/HuOqPT

3. World Meteorological Organization Climate Knowledge for Action: A Global Framework for Climate Services - Empowering the Most Vulnerable Report No. 1065 (WMO, 2011).

4. American Meteorological Society Climate Services: A Policy Statement of the American Meteorological Society (AMS, 2012); available via http://go.nature.com/OrPVIW

5. Beddington, J. Review of Climate Science Advice to Government and Met Office Hadley Centre Role, Governance and Resourcing (Government Office for Science, 2010); available via http:// go.nature.com/z2aghR

Published online: 28 October 2012 